\title{
Forms of Science Capital Mobilized in Adolescents' Engineering Projects
}

\author{
Amy Wilson-Lopez \\ (corresponding author) \\ Utah State University \\ School of Teacher Education and Leadership \\ 2805 Old Main Hill \\ Logan, Utah, 84322-2805 \\ (801) 633-7638 \\ amyalexandra.wilson@usu.edu
}

\section{Christina Sias}

Utah State University

csias@,intechchs.org

\author{
Allen Smithee \\ Utah State University \\ asmithee@alpinedistrict.org

\section{Indhira María Hasbún} \\ Virginia Tech \\ imhasbun@vt.edu
}




\begin{abstract}
The purpose of this multiple case study was to identify the forms of science capital that six groups of adolescents mobilized toward the realization of their self-selected engineering projects during after-school meetings. Research participants were high school students who selfidentified as Hispanic, Latina, or Latino; who had received English as a Second Language (ESL) services; and whose parents or guardians had immigrated to the United States and held working class jobs. The research team used categories from Bourdieusian theories of capital to identify the forms of science capital mobilized by the participants. Data sources included transcripts from monthly interviews and from bi-monthly group meetings during which the group members worked on their engineering projects. Data analysis indicated that the groups activated science capital in the following categories: embodied capital in the form of formal scientific knowledge, literacy practices, and experiences with solving everyday problems; social capital in the form of connections with authorities, experts, and peers; objectified capital in the form of information and communication technologies (ICTs) and measuring tools; and institutional capital in the form of awards and titles. The participants co-mobilized multiple forms of science capital to advance their engineering projects, and some instances of co-mobilization enabled the future activation of subsequent forms of science capital. Engineering, as a vehicle for learning science, provided the youth with opportunities to draw from diverse community resources and from multilingual literacy practices, recasting these resources and skills as forms of science capital, which were mobilized toward the attainment of other high-status forms of science capital.
\end{abstract}

Keywords: science capital; Bourdieu; engineering; literacy practices; bilingualism 


\section{Forms of Science Capital Mobilized in Adolescents’ Engineering Projects}

Youth whose families possess science capital—or social and cultural resources that support their participation in science - are more inclined to aspire to science-related careers than youth whose families do not possess science capital (Archer et al., 2012; Archer, DeWitt, \& Willis, 2014; Archer, Dawson, DeWitt, Seakins, \& Wong, 2015). Unfortunately, one implication of this finding is that science-related careers continue to be distributed along classed lines (Gorard \& See, 2009). For instance, children whose families can afford tickets to science museums and subscriptions to science-related magazines are more likely to pursue sciencerelated careers than children whose families cannot afford forms of science capital (Archer et al., 2015). Class frequently intersects with race, citizenship status, and language proficiency, as particular groups are often denied positions that grant the economic capital necessary to purchase many forms of science capital. In Bourdieu's (1986) words, “Economic capital is at the root of all of the other types of capital" (p. 54), including science capital.

At the same time, what counts as capital is dependent upon legitimization by others (Carrington \& Luke, 1997; Claussen \& Osborne, 2013; Skeggs, 2004). Capital that is not valued within one field may be deemed as valuable within another field. Thus, many working class youth may possess many skills, bodies of knowledge, objects, and social connections that could be considered science capital if they were legitimized and used as such. Working under this assumption, we sought to identify the types of science capital possessed by people who have been historically underrepresented in scientific fields: Latinxs who spoke English as a second language and whose guardians/parents were immigrants with working class jobs. Specifically, the purpose of this study was to describe how adolescent groups mobilized configurations of science capital toward their engineering projects, which they marketed to potential investors. 


\section{Engineering and Equity in Science Education}

Theories of science capital foreground inequity by explaining why middle class people hold a disproportionate number of jobs in science, technology, engineering, and mathematics (STEM) fields. Though many structural and pedagogical approaches might combat this inequity, youth-driven engineering is one promising avenue for promoting long-term equitable outcomes (Rodriguez, 2015)—such as the participation of more working-class Latinx immigrants in STEM careers - which typically offer more financial security than other careers (Greenwood, Harrison, \& Vignoles, 2011; National Science Board, 2016). The authors of the Next Generation Science Standards (NGSS) (NGSS Lead States, 2013), which have been adopted in many states across the US and which have informed standards in many other states, explained that they foregrounded engineering in order to promote equity and diversity. They argued that whereas previous national standards privileged scientific practices that "happened to develop in Europe" (American Association for the Advancement of Science, 1989, p. 136), engineering practices more fully legitimize and incorporate the ways in which historical and contemporary families, communities, and societies have iteratively developed tools, processes, and systems to meet their needs - a hallmark of engineering (Dym, Agogino, Eris, Frey, \& Leifer, 2005).

While affirming the potential for engineering to promote equity, Rodriguez (2015) stated that "good teachers and researchers/teacher educators have been promoting engineering practices in their classrooms and/or research projects all along," albeit in ways that "never specifically called these practices engineering" or distinguished between engineering and science (p. 1036). Many equity-oriented studies with underrepresented youth seem to confirm this statement. For example, Maulucci et al. (2014) described how Leonardi, a Dominican middle school student in an urban setting, developed a sustained interest in science when he designed a garbage disposal 
machine. Hammond (2001) described a program in which pre-service and practicing elementary science teachers, Mein-American immigrant students, and their families worked together to design and construct a Mein-American garden house, which became a source of pride for the community. Rodriguez and Berryman (2002) described how Mexican American high school students in a border community developed positive attitudes toward science and were more likely to consider pursuing STEM careers after they compared water treatment approaches and later purified water.

These studies and others, conducted both in school (e.g., Lim \& Calabrese Barton, 2006; Zimmerman \& Weible, 2017) and out of school (e.g., Basu \& Calabrese Barton, 2007; Fusco, 2001; Licona, 2013) over the last two decades, shared at least two similarities. First, many authors described how underrepresented youth engaged in activities typically associated with engineering, such as evaluating competing solutions or designing and realizing solutions to problems using science, but they did not explicitly frame these activities in terms of engineering practices. Second, these studies indicated that engineering can build underrepresented students' sustained interest in STEM by demonstrating how science can be applied toward transforming real problems or meeting real needs in households or communities; and/or by activating and legitimizing local and cultural knowledge and practices, such as local water purification techniques or culture-specific architectural practices. In turn, underrepresented students who have developed a sustained interest in science are more likely to enter the STEM workforce.

Collectively, these studies indicated the promise of engineering to promote equitable outcomes in society, such as the increased participation of underrepresented students in STEM. Inspired by these studies, we sought to engage underrepresented youth in engineering as a promising vehicle for promoting their interest in STEM. Because these previous studies did not 
explicitly foreground engineering practices, we intended for this engineering-focused study to more fully illuminate the ways in which engineering practices fostered the legitimization and activation of youths' cultural knowledge and practices.

\section{Funds of Knowledge and Capital}

Many scholars (Basu \& Calabrese Barton, 2007; Fusco, 2001; Licona, 2013; Maulucci et al., 2014; Zimmerman \& Weible, 2017) have used the term 'funds of knowledge' when describing how (implicit) engineering practices can incorporate and legitimize local and cultural knowledge. In their seminal work on funds of knowledge, Moll and colleagues (Moll, Amanti, Neff, \& González; cf. Vélez-Ibáñez \& Greenberg, 1992) described several categories of culturally-derived bodies of knowledge and skills, or funds of knowledge, which Mexican American immigrants had developed to survive and thrive, such as knowledge of building codes, budgets, and construction — knowledge which, we argue, is more directly related to engineering design than to scientific inquiry (Bybee, 2011). Funds of knowledge have been distinguished from capital in part because funds of knowledge have "everyday use value," in the sense that they help families survive and thrive, whereas forms of capital can be mobilized to generate other forms of high-status capital (including money) that are valued by dominant groups (Kiyama, 2010; Rios-Aguilar, Kiyama, Gravitt, \& Moll, 2011). Thus, what is considered a "fund of knowledge" — such as knowledge of building codes — may be converted into science capital when it is activated toward the attainment of other forms of science capital (Smith \& Lucena, 2016).

We framed this study in theories of capital, rather than in related funds of knowledge frameworks, under the recognition that some bodies of knowledge lead to a privileged place in society more so than others - that is, possession of funds of knowledge does not necessarily 
convert into economic capital (Lubienski, 2003). Many previous studies with working class youth have used a "funds of knowledge" perspective rather than a "capital perspective" (RiosAguilar et al., 2010), but this framework may not fully illuminate how underrepresented youth possess and activate potentially high-status and valuable forms of science capital. Much as Lopez (2001) found that Latinx families often support their children's educational development in ways that "lie outside of traditional school-related models" (p. 416; cf. Ruiz-de-Velasco, Fix, \& Clewell, 2000), we sought to describe how Latinx youth from immigrant families mobilized forms of science capital, which may not have been fully described in previous models of science capital, towards youth-driven engineering projects with the potential to result in additional science capital.

\section{Forms of Science Capital}

Science capital can be defined as any form of capital that is directly applied, exchanged, or converted as people pursue advancement or achievement in science-related fields such as engineering. Archer and colleagues (2015) argued that science capital is increasingly valuable in contemporary societies where STEM professions hold a place of symbolic prestige (cf. Martin, 1998). Bourdieu asserted that economic capital — either by itself or in any of its converted forms - enables people to obtain respected positions in society, and indeed, money has long been tied to educational attainment in general (Lareau, 2011; Reay, David, \& Ball, 2005) and to science and engineering careers specifically (Gorard \& See, 2009). Other scholars (Cherng, Calarco, \& Kao, 2013; Compton-Lilly, 2007), however, have challenged the centrality of economic capital in Bourdieu's theories, arguing instead that working class people possess other forms of capital—particularly social or cultural capital—which enable them to achieve valued goals and positions within particular fields. In accordance with this assertion, the following 
section outlines how various forms of social and cultural capital can aid people in reaching desired outcomes in scientific fields such as engineering.

Social capital. According to Bourdieu (1986), social capital can be defined as resources that stem from relationships characterized by mutual recognition. Drawing from this definition, Lin (2000) emphasized that these resources are mobilized toward purposive actions - in the case of this study, toward engineering projects. As people seek to accomplish a given goal, social capital can facilitate information sharing, influence others with decision-making power, and provide them with support that helps them to persist in achieving their goals (Davis, 2001; Lin, 2001). Martin, Simmons, and Yu (2013) found that, although the Latina undergraduates in their study demonstrated a "lack of available family social capital" relevant to engineering (p. 227), they possessed other forms of social capital that aided them as they sought to obtain engineering degrees. For instance, peer capital helped them to succeed at open-ended engineering tasks as they exchanged scientific information and other forms of knowledge with each other (cf. Brown, Flick, \& Fiez, 2012; Prewitt, Eugene, \& Daily, 2007).

In addition to peer capital, many underrepresented youth benefit from the social capital provided by adult mentors who embody a passion for science and engineering and who help them navigate institutional structures required to register for college courses in these fields (Martin, 2015). In Martin et al.’s (2013) study, working class Latina undergraduates credited middle or high school teachers who inspired them to pursue engineering and who helped them to understand the college application process. Fuller (2011) likewise found that adult mentors were important social resources that encouraged underrepresented adolescents to aspire to and persist in STEM careers. Collectively, these studies highlight that peer and adult networks can foster underrepresented students' interest and success in scientific fields. 
Objectified capital. Like social capital, cultural capital also supports achievement in STEM fields. In Forms of Capital (1986), Bourdieu outlined three categories of cultural capital: objectified, institutional, and embodied. Objectified capital includes objects such as "pictures, books, dictionaries, instruments, [and] machines" that denote status in a particular field or that can be converted into other forms of capital within that field (p. 47). Archer and colleagues (2012) identified electronic sets and scientific magazines in the home as forms of objectified science capital. Importantly, objectified capital extends beyond physical objects to include the ability to appreciate, consume, use, or those objects appropriately. For instance, parents who describe themselves as "quite sciencey" (Archer et al., 2012, p. 892) may discuss scientific magazines and television in the home; the tendencies to discuss the magazines are enfolded within the category of objectified capital. Objectified capital is converted to embodied capital when youth acquire knowledge of scientific principles and applications through interactions with science-related objects and when they acquire a growing appreciation for and facility with those objects.

Institutional capital. Institutional capital includes titles, awards, degrees, or other designations that institutions confer upon individuals. Many current descriptions of institutional science capital relate to parental science qualifications (e.g., Archer et al., 2015), rather than describing how youth may themselves possess institutional capital, perhaps because a primary form of institutional capital is the college degree (Naidoo, 2004), which is typically conferred in adulthood. This form of capital signifies "officially recognized, guaranteed competence" (Bourdieu, 1986, p. 51), including in science and mathematics. Unfortunately, a disproportionately low number of Latinxs receive college degrees in STEM-related fields, 
(Lichtenstein, Chen, Smith, \& Maldonado, 2014) a number that is even lower for those from immigrant families (National Center for Educational Statistics, 2012).

Embodied capital. Embodied scientific capital includes durable bodies of knowledge, skills, or behaviors that are acquired over time, such as knowledge of scientific principles or the ability to design experiments and tests whose conclusions would be recognized as valid by one's peers. However, embodied capital encompasses more than bodies of knowledge and skills; it also includes durable inclinations toward particular kinds of activities. Bourdieu (1986) asserted that embodied capital includes "external wealth converted into an integral part of the person, into a habitus" (p. 48), which can be defined as an internalized roadmap for action with encoded beliefs, values, and dispositions toward certain practices (Bourdieu, 1984, 1998).

In elaborating on the term family habitus, Archer and colleagues asserted that some families develop taken-for-granted identities that science is a part of 'who we are' and 'what we do.' These families engage in everyday practices such as discussing science-related news and television shows; sharing what happened at work in their science-related careers; visiting zoos, museums, and science-related exhibits for recreational purposes; or playing with engineeringbased toys. These activities develop children's 'feel' for science and engineering. In short, these families value science and regularly embody the belief that science is attainable and even routine. Youth from families with a science-friendly habitus are more likely to aspire to sciencerelated careers than those from families who do not enact similar practices and values.

Relationships between forms of capital. Bourdieu (1986) asserted that forms of capital are convertible, in the sense that one form of capital (e.g., a college degree) may translate into another form (e.g., money). They are also exchangeable in the sense that people can apply one form of capital in place of another while working toward the accomplishment of the same goal. 
In explaining this principle, Bourdieu and Wacquant (1992) compared multiple forms of capital to cards in a game that players seek to win. They specified that the cards hold differing relative values, which are dependent upon the field in which they are played. According to this metaphor, people play their cards as they seek to achieve desired goals and positions within a given field. Thus, if they do not have one desirable card or form of capital, they can play other cards in its stead as they seek to advance in the game. Working under this theory, we sought to identify how the youth mobilized configurations of capital, rather than single types of capital, toward their engineering projects. We intended for this holistic view of capital mobilization to contribute to existing theories of science capital (e.g., Archer et al., 2015), which have often described individual forms of capital in discrete categories, rather than illustrating how they can be mobilized and exchanged toward a concerted end.

\section{Participant Selection and Description}

We recruited participants from after-school clubs geared toward Latinxs, such as Latinos in Action. In our recruitment speech, we shared engineering projects completed by youth with whom we had previously worked, and we stated that participants could work with engineers after school to select problems in their communities and develop their own engineering projects as solutions to these problems. The youth who returned their consent forms cited several reasons for wanting to participate in this study: to learn more about engineering as a potential career choice, to make a difference in their communities, and/or to improve college admissions prospects. We selected 22 adolescents to participate in this study because they met the following criteria: They identified themselves as Hispanic, Latina, or Latino; at least one of their parents or guardians had emigrated from another country; and their guardians held working class jobs. We established these criteria because relatively few Latinxs from immigrant families pursue STEM careers 
(Lung, Potvin, Sonnert, \& Sadler, 2013; National Science Board, 2016), and we sought to understand how youth from this underrepresented group possessed forms of science capital.

The participants, ranging between the ages of 14 and 17, lived with their parents or aunts who commonly held jobs related to the farming industry, such as "patting...cutting... and stocking cheese" (Luciana); "moving and killing chickens" (Natalia); "milking cows" (Diego and Martín); "fixing the cutting machines that roll down the meat through the lines...at a factory where they make meat" (Teresa); "carrying the body of the cow up to hooks" (Silvia); and "welding at the egg farm" (Luis). (All names are pseudonyms.) Fifteen of the participants also worked for farms, meat processing plants, or food preparation venues. All spoke Spanish at home, although three participants also spoke English with one parent. Each participant lived with at least one parent or guardian who had immigrated from Guatemala, Honduras, Mexico, or El Salvador, and many still had siblings and parents who lived in those countries. Prior to the study, three participants had taken a pre-engineering class required at their high school. They described this class as learning how to use drafting software to produce objects specified by their teacher. All of the youth had taken required science classes appropriate to their grade level, including earth science, biology, and chemistry. Eight participants had also taken additional elective science courses, such as physics and medical anatomy.

\section{Research Team}

Two engineers, both of whom emigrated from Latin American countries, facilitated afterschool, bi-monthly group meetings with the youth. To introduce the participants to engineering design, at the first group meeting, they shared problems that had been addressed through different disciplines of engineering. They also led the participants through an activity that required them to apply engineering design processes to an imagined problem. After this initial 
meeting, the engineers did not provide any suggestions. Instead their role was to guide discussion through asking open-ended questions, such as "What do you think about Natalia's solution?" The engineers assumed this role to ensure that the research team could identify forms of science capital that the youth held in their existing social networks, rather than relying primarily on the engineers as sources of information. Author 1, a specialist in literacy and culturally responsive STEM education, designed the study, and she orchestrated and participated in data collection and analysis. Author 2, a high school teacher at a STEM-focused charter school, and Author 3, a science teacher in a Spanish/English dual immersion program, analyzed data, while Author 4, an engineer who spoke Spanish as her first language, collected data.

\section{Method}

In order to answer the research question, How did the youth mobilize configurations of science capital toward their engineering projects?, we conducted a secondary analysis of data from a larger study of the engineering experiences of Latinx youth (Wilson-Lopez, Mejia, Hasbún, \& Kasun, 2016). This sub-study was conducted with 22 working class Latinx high school students, each of whom lived with a parent or guardian who had immigrated to the rural Western United States from Central or South America. The youth met in teams, each of which was comprised of three to four people, twice per month for about nine months. Each team served as one case, enabling us to conduct a multiple case study (Yin, 2014) by comparing and contrasting different forms of science capital within and across cases.

During voluntary after-school meetings, the participants identified problems in their communities that could be solved through engineering, developed solutions to those problems, and shared their ideas with potential funding sources. All seven teams initially discussed and pursued multiple engineering projects, which are outlined in Table 1. We did not impose time 
limitations on the projects, but all groups opted to end their projects at the end of the academic year due to various commitments they had over the summer. Because the participants could not pursue all of their proposed projects in a nine-month period of time, they ultimately chose one problem to collectively pursue, and they presented a design solution to potential clients or investors of their choosing. We summarized all of their proposed projects (not just their completed projects) in Table 1 because many of the groups spent several weeks or months on one project before switching to another project and because some participants individually pursued their groups' proposed engineering projects on their own time, outside the scope of the group meetings.

Insert Table 1 about here.

\section{Data Sources}

We collected three types of data. First, we audio- and video-recorded bi-monthly group meetings, which were held in community spaces chosen by the participants, such as at local libraries or recreation centers. These meetings, which lasted an average of two hours each, were conducted in Spanish or English according to each group's preference. We also followed the participants to their data collection sites, such as local businesses where they interviewed employees about existing materials and devices. Second, we collected artifacts generated by the participants, such as lists of Internet sites they visited, photographs of sketches they drew or physical prototypes they constructed, and PowerPoint presentations they shared with potential economic benefactors. We provided the participants with a tablet computer that they kept for the duration of the study. We did not analyze the artifacts but used them to inform the third data 
source: monthly individual interviews with each participant. The interviews, which were conducted in the participants' language of choice, were designed to further ascertain the forms of capital mobilized by the participants.

We used the youth-generated artifacts and the transcripts from previous group meetings as the basis for follow-up questions in the monthly individual interviews. For instance, we asked one participant, "In the group meeting, you had said that your dad recommended that you use hollow steel for the frame of your cat-nabber [her group's self-selected engineering design project]. Will you tell me more about why your dad said that and what you learned from him?" During several interviews, we also displayed the youth-generated artifacts and used them as the basis for interview questions, such as when we displayed slides of a PowerPoint presentation and asked the participants to tell us about the resources that helped them to make it.

\section{Data Analysis}

We began our analysis of the bi-monthly group meetings and individual interviews by reading through the data and asking, "How are the youth mobilizing capital toward their engineering projects?" We thematically segmented the data by delineating every new instance in which participants used one or more resources (e.g., knowledge, social connections) to advance one aspect of their engineering project. The following example will illustrate how we segmented and then coded the data. Members of Group Six interviewed an employee at a local hardware store regarding the type of mesh they should choose for their cat restraining device and regarding the type of material that should form the frame of the restraining device.

We divided this interview into two thematic segments: one segment addressed their efforts to move forward with their project by deciding on mesh materials (one aspect of the engineering project); and a second segment addressed their efforts to move forward by deciding 
on frame materials (a second aspect of the engineering project). After dividing the transcript from this interview into segments, we used Bourdieu's (1986) framework of types of capital to assign each segment with one or more superordinate codes: social, embodied, objectified, or institutional. In this case, each interview segment was coded once as social capital because the participants relied on a social resource in their community to advance one aspect of their engineering project. After applying these superordinate codes, Authors 1, 2, and 3 read through randomly selected data excerpts and developed sub-categories under each of these four a priori categories based on patterns they noticed in the data.

For example, among all data segments that had been assigned social capital, we noticed that the participants leveraged social resources in different ways: They mobilized some resources for their expert knowledge, some for their ability to actualize their projects, and some as friendly peers who helped them to brainstorm ideas. Under the superordinate category social capital, we therefore developed and defined the sub-categories authority, expert, and peer (See Table 2). We often assigned only one superordinate and sub-category to each segment of data, but these codes were not mutually exclusive.

Finally, if we had already identified and counted how a particular resource was mobilized for one aspect of an engineering project, we did not count it again if it appeared later in the data set. For instance, although members of Group Six referred back to what they learned from the employee in subsequent interviews, we did not count the content of these later interviews as new instances of social capital: expert because the participants did not mention how they had used the employee's advice for a new aspect of their engineering project, beyond material selection for the mesh and frame, and we had already counted the ways in which they leveraged this social resource for this purpose. 
As a second example to illustrate our coding process, we often observed group meetings in which the participants analyzed multiple surveys or entered multiple terms into an Internet search engine. Rather than counting each survey or search term as a different instance of capital, we divided the data into segments indicating how this resource was used to advance one aspect of an engineering project. For instance, Group One distributed 60 surveys to their peers, in which they asked for feedback on how to improve their wheelchair-accessible swing. They discussed these surveys during several group meetings. We divided the transcript of one group meeting into two segments: one delineated by decisions regarding how steep the ramp should be (one aspect of the engineering project) and a second delineated by decisions regarding how they might make the experience aesthetically enjoyable for the client (a second aspect of the engineering project). The group used responses from multiple people to decide that that their existing ramp was too steep, which was coded and counted once as social capital: peer. They also used responses from multiple people to decide that they should design a swing that would allow riders to more fully see the scenery around them in order to give them a more aesthetically enjoyable experience. We coded and counted this segment once as social capital: peer.

Table 2 provides a definition for each category of capital and an example of data that had been assigned to that category. After developing these categories, Authors 1 and 2 independently coded $20 \%$ of the data and achieved $90.4 \%$ agreement in their codes, an indication that they were reliable (Saldaña, 2015). No new categories emerged, indicating that data saturation had been reached. Author 1 then coded $40 \%$ of the remaining data, while Author 2 coded the other $40 \%$ of the remaining data. To confirm that these codes remained reliable, Author 3 (who was not involved in data collection) conducted an external audit by reading through randomly-selected 
data points and confirming that our codes fit the data. We also shared the findings with available research participants who confirmed that our analysis cohered with their perceptions of the data.

Insert Table 2 about here.

\section{Limitations}

We are adults with advanced college degrees who affiliate with academic institutions, such as high schools and universities. As such, we acknowledge that we inserted our own forms of capital into the study. For instance, we wrote several letters of recommendations for participants in support of their college scholarship applications. In this instance and others, we in effect became a form of social capital for the youth as they sought to pursue their goals. We also provided the youth with material resources such as computer tablets and (if they did not already have it) wireless Internet access in their homes to enable them to work on their engineering projects outside of school. In this way, we limited the transferability of our results, or its ability to produce knowledge that is meaningful in other contexts (Miles \& Huberman, 1994; Walther, Sochacka, \& Kellam, 2013), because many working class Latinx youth from immigrant families do not have teams of university researchers and engineers present to support them in their science-related endeavors. Nevertheless, we found that the participants activated many resources beyond those associated with our research team, and consequently, the findings from this study may be of interest to other stakeholders who work with Latinx youth from working class immigrant families.

\section{Findings}


We present our findings in two ways. First, we use a frequency count in Table 3 to provide an overall picture of how different groups mobilized different configurations of capital. This table suggests that no two groups mobilized the same configurations of capital: Different groups activated different categories of capital to different extents. Second, in our descriptions below, we qualitatively describe how different groups co-mobilized particular types of capital toward aspects of their engineering projects, and (where applicable) how used these forms of capital to offset the absence of other types of capital. In each section below, we foreground the type of capital stated in the sub-heading, but we also indicate the co-activation of other forms of capital (identified in our coding scheme) by highlighting these secondary forms of capital in italics. We present the data in this holistic way in accordance with Borudieu's theory that forms of capital, like cards, are often played together, and we wanted to illustrate how different groups co-mobilized sets of science capital.

Insert Table 3 about here.

\section{Social Capital}

As indicated by Table 3, all groups possessed social capital related to science. They drew from their connections with experts, authorities, and/or peers in order to help them complete their engineering designs.

Connections with experts. Many groups did not believe that they knew enough about relevant scientific principles in order to successfully complete their engineering projects. As an example, for their cat-nabber device, Group Six wanted to use metal that met the following criteria: It must be inexpensive so that veterinary clinics could purchase the device, lightweight 
so that people could lift the cat with minimal exertion, strong enough that it could lift large cats without bowing, and able to be magnetized so that two pieces would clasp together and hold the cat. Because they did not know which metals held these properties, which would have been a form of embodied scientific knowledge, they used literacy practices, such as their familiarity with conducting Internet searches, to identify metals that possessed these properties.

After the group had searched the Internet for over an hour without finding sites they felt were useful, Natalia suggested that they instead search for apps for their computer tablets. She located and downloaded a reference app, indicating her familiarity with using ICTs to solve problems. This app included a table that described the properties of different metals. The following excerpt was taken from an interview with Natalia in regards to this reference app:

Interviewer: Earlier you said you didn't know what Conditioner A means. Is there anything else here that you don't know what it means?

Natalia: Yeah, what they're talking about. Just like basically everything what they're talking about. Like elongation and hill stress, I don't know what that is, and strength. And then AISI, what that stands for.

Interviewer: Yeah, it does seem like it's for people who already have a lot of background knowledge. So it would be hard based just by looking at this [table] to make a decision [regarding which metal should be used for a cat-nabber frame].

Natalia: My dad would simplify it for me.

In this exchange, Natalia indicated that she did not understand the table in large part because she was not familiar with the scientific terminology in the headings. To learn more about metals, Natalia later interviewed her father, a metal-worker, in Spanish. After outlining the pros and cons of different metals, he recommended ferritic stainless steel because it met the established criteria 
and because it was rust-resistant and relatively easy to obtain. The group followed his recommendation by selecting this material for their restraining device.

In her final interview, Natalia's group member Isabella confirmed, "I discovered new resources to find a solution. I realized that it's better to ask (people) because the Internet is just frustrating. So it's better to ask around because it gives you more of a direct answer." In this quotation and others, Isabella and her group members indicated they valued and used the knowledge they obtained from experts in their community more than they valued the knowledge they obtained from other resources, such as through Internet searches or apps. In Bourdieusian terms, Natalia and her group initially sought to mobilize embodied and objectified capital, such as their knowledge of how to conduct Internet searches and their knowledge of how to use apps, toward the production of their engineering designs. However, when this strategy for using literacy practices and ICTs proved to be unsuccessful, they mobilized social capital in order to obtain the information they needed to complete the project.

Connections with authorities. The participants consciously activated social capital to advance their aspirations. To this end, they told each other about a Hispanic college admissions advisor they knew who "helps Hispanics"; they purposefully sought to cultivate relationships with professors they met at summer science camps; and they joined youth organizations that would provide them with access to prominent city figures, such as the mayor. Diego stated that, from the time he was a middle school student, he closely observed the adults at his school to determine "which really do care and which don't really care." Diego had identified his principal as somebody who "cares about Hispanics," as evidenced by the fact that he continued to fund, support, and periodically visit meetings of the Latinos in Action program, even after other high schools in the district had eliminated this program. 
Prior to the study, Diego visited the principal during study hall and spoke with him in Spanish. This principal sometimes allowed Diego to sleep in a cot in the counseling office because he was tired from waking up at 3:30 am to milk cows before school and then working in a car mechanic's shop after school. Diego activated this social resource, which he had carefully cultivated over the past several years, in order to help him complete the engineering project, which was designing a wheelchair-accessible door for students at his school.

Throughout the project, Diego frequently consulted his principal who introduced him to custodians. These custodians acted as experts by sharing information about maintenance and regulations related to doors. The principal also stated that he would help Diego attend a meeting with district administrators in order to pitch his design idea to them. Luis, a member of Diego's group, was required to write a grant application in his English class during the previous year, so he used what he had learned from that assignment to write a grant for the district administrators, after viewing models of grants that the principal had previously written. In sum, Diego's connections with the principal led to other forms of social capital: connections with experts (the custodians) and connections with other authorities (district administrators). The group also mobilized literacy practices, including their knowledge of how to write in the genre of grants, in conjunction with the social capital obtained through the principal, when they sought to present their ideas to district stakeholders.

Connections with peers. As indicated by Table 3, all groups drew from their connections with peers less frequently than they drew from their connections with experts, but peer-based resources nevertheless informed each team's engineering design. All participants had built numerous connections with other high school students through school, after-school clubs, church groups, and family networks, and at times they drew from peer capital when they faced 
the absence of other forms of capital. Members of Group One drew from peer resources as they sought to develop improved playground swings for children in wheelchairs. They had drawn an initial image of a swing, and they wanted to make sure that this design would be well-received by the head of the local Parks and Recreation Director to whom they would later present their idea.

However, they did not know any engineers who could give them feedback on their design ideas, and the engineers who facilitated their weekly group meetings did not want to unduly influence the project by sharing design ideas with them. To work around this challenge, members of Group One collectively wrote a survey that they copied and distributed to over 60 students at their high school. This survey included an image with the question: "What is your opinion on this wheelchair swing? How could it be improved?" Their peers responded with numerous criticisms and suggestions, ranging from questions about whether young children could wheel themselves up the steep ramp, to ideas for improving the children's aesthetic experiences so they could see more scenery as they were swinging. In Bourdieusian terms, although this group did not activate existing connections with experts as a form of social capital, they co-mobilized other forms of capital—such as their connections with peers (social capital) and their ability to create and interpret the results of surveys (embodied capital in the form of literacy practices) to achieve their goal of obtaining useful feedback.

\section{Embodied Capital}

As indicated by Table 3, all groups possessed forms of embodied science capital that were relevant to their engineering designs. Although many practitioners have defined engineering in large part as the application of formal mathematical and scientific principles (Pawley, 2009), we found that the participants did not often draw from formal scientific or 
mathematical knowledge to produce their designs. Instead, they relied on other forms of embodied capital, such as their ability to read and produce texts in English and Spanish and their familiarity with solving a wide range of problems in their households and communities. In the following section, we describe how the participants had developed a habitus that was conducive to engineering design, and we describe how they possessed and drew from embodied capital to produce their designs.

Habitus. The participants' families fostered a habitus — or a "set of durable dispositions or tendencies to act and think in certain ways" across multiple situations (Kramsch, 2008, p. 38) —which was conducive to aspects of engineering design. Specifically, all participants' families exhibited a 'do-it-yourself habitus' in the sense that they had instilled a strong sense of selfreliance in their children. The following quotation by Silvia, in which she described why her family delivered her dog's pups, illustrates this do-it-yourself habitus:

We didn't take her [the dog] to a veterinarian. We did it by ourselves because when our dog got pregnant, we were living in the trailers. This neighbor said that she had done it by herself. Our dog was pregnant and we didn't want to pay, at that time money was tight [...] We just called her, and she showed us how to do it and what would happen. We did it by ourselves [...] My parents have had a really tough life, so for them to actually spend money on something that would not really benefit them, if they could do it, they would rather do it.

In this quotation, Silvia indicated that her family did not want to spend their limited economic capital on hiring others for jobs they could do themselves. She articulated that their family sought to live by a do-it-yourself principle in general, which in this case meant that they wanted to deliver a pup by themselves rather than hire a veterinarian. 
This do-it-yourself habitus was prevalent across participants' families, and it fostered the development of science capital. Because the participants' families emphasized doing it themselves, the participants had independently solved a wide range of problems in their households and neighborhoods: They fixed broken cars; designed and installed fences; lifted and moved heavy sheds; and realized projects that required the use of a variety of measurement and construction tools. At times, as part of the process of "doing it by ourselves," the participants conducted Internet searches, and they read or viewed numerous websites with tutorials for fixing problems, some of which included scientific information. In this way, many participants developed literacy-related science capital, or the ability to interpret and apply information from complex technical texts, as they repeatedly sought to solve their own problems.

Everyday problem solving. Several participants cited their previous experiences with solving problems in their households or workplaces as the basis for their engineering projects. Although individual groups did not communicate with other groups, three of the six groups initially wanted to design a community garden for their projects. The groups pursued this idea because they had experiences with household gardens, which included a range of fruits and vegetables such as green chili, jalapeños, cucumbers, beans, garlic, watermelon, pumpkins, cilantro, raspberries, and strawberries. Oftentimes, the participants' plants did not grow as expected, and they had attempted to conduct controlled experiments to diagnose and develop solutions to this problem. Different participants described a range of factors that prevented their plants from growing, such as a family goat that "basically ate all of the garden," infertile soil, freezing temperatures, inadequate sunlight, and soil erosion.

Teresa attempted to address several of these factors as she tried unsuccessfully to grow strawberries over the course of several years. She described her iterative testing process: "If it 
doesn't turn out then I go back in my mind and be like 'What was the part that I'm missing? Or what did I do wrong?'" One year she gave two different fertilizers to the plants to observe how each fertilizer affected their growth. However, during that same year, the plants were located in the path of rainwater expelled from the gutter. Because it appeared that soil erosion, rather than fertilizer type, led to unsuccessful outcomes, she subsequently placed the strawberry plants in a different part of the yard. Despite her use of different fertilizers, the plants exhibited minimal growth. She reflected on other possible causes for the plants' failure to thrive, such as the "bugs in the garden" that she observed. In a later season, therefore, she used pesticides on the strawberry plants, but a family member inadvertently ran over them with a car. She noted that this accident, in turn, limited her ability to determine the pesticides' influence on the strawberries.

Throughout this process, Teresa sought to design valid experiments in which she isolated single variables, made observations, developed tentative conjectures in regards to causation, redesigned experiments, and developed evidence-based explanations. Teresa's group mobilized this embodied capital when they initially considered building a community garden for their engineering project. Drawing from their previous experiences with gardening, they noted that a community garden would need to be placed on flat land and in an area with minimal water runoff in order to minimize soil erosion caused by water. They further emphasized the need to address potential animal and human interference of many kinds, a problem they sought to solve through selecting a safe location and designing a fence. Unsure of a place in their community that met these criteria, Teresa consulted her parents who acted as experts on community geography by identifying promising locations. Although the group ultimately abandoned the idea to produce a community garden, they activated multiple resources toward the pursuit of this goal, such as their 
connections with experts in the community and their knowledge gained from everyday problem solving with plants.

Formal scientific knowledge. As indicated by Table 3, the groups applied formal scientific knowledge less frequently than they drew from other forms of embodied capital. Moreover, the participants usually expressed uncertainty about their scientific knowledge. For instance, Group Two sought to determine "how much force we need" to open an internal door to their high school so that wheelchair-bound students could pass through it. When considering how to measure force, Diego and Martín remembered that they had discussed methods for calculating force in their physics class. The following excerpt from their group discussion demonstrates how they tried to recall these methods:

Diego: You would take

Martín: Gravity?

Diego: Gravity goes into the equation, but so like look, I'm gonna show you here [begins to write out equation]....I don't know how this equation goes. I remember all this; I just can't remember. There's an equation you use to determine how much force it's going to take to pull it.

In this quotation and others, this group demonstrated an awareness of the concept of force, and they knew that formulas for measuring force existed, even if they did not remember what those formulas were. Martín later asked his physics teacher to help his group apply the formula for measuring force.

In this example, the participants' nascent awareness of scientific principles enabled them to generate questions for an expert. This expert, in turn, provided advice on how to measure the amount of force that it took to open the door. In Bourdieusian terms, the participants did not 
believe their existing scientific knowledge, a form of embodied capital, enabled them to figure out how much force was needed to open the door. However, they activated this existing scientific knowledge (e.g., an awareness of formulas) in conjunction with their connections with an expert in order to determine how much force was needed in order to open the door, a calculation that later informed their final design.

Literacy practices. As indicated by Table 3, all groups mobilized literacy practices as a resource for their engineering projects at least three times more often than they mobilized formal scientific knowledge. As an example, Group Three wanted to improve existing headrests for shower chairs (devices that help people with disabilities to enter and exit bathtubs). They sought to select appropriate materials for the base of the headrest, but they did not know the names or properties of promising materials. As a starting point for their search, they interviewed the manager of an assisted care facility (an expert) who explained that many of his residents entered and exited the shower while sitting on chairs made out of PVC (polyvinyl chloride).

After learning the name of this promising material, Teresa entered "PVC" into an Internet search engine. This search term initially resulted in websites designed to sell PVC, and consequently, Teresa modified her search until she found websites that outlined the properties of PVC by reading their descriptions on the search engine page. Based on the information she obtained from this Internet search, she identified PVC pipe as an appropriate material for the head rest because it was "not expensive," "you can put it in higher temperatures" and it would stay cool to the touch, and it "doesn't rust." In Bourdieusian terms, when faced with the absence of formal scientific knowledge about particular materials' properties, the group co-activated social capital (an expert) and embodied capital (literacy practices) in order to arrive at a decision regarding their engineering project. 


\section{Objectified Capital}

The participants' literacy practices interacted with their objectified capital in the sense that they used various objects in the process of locating, interpreting, and communicating relevant knowledge. We identified two primary forms of objectified capital in this data set. First, all participants used various information and communication technologies (or ICTs) - most commonly, smart phones and computers with their associated apps, games, and software - to acquire or communicate scientific information. All participants owned a smart phone at some point during the study, and all participants had access to a computer with Internet access at home or at school. Second, many participants used a variety of measurement and construction tools at their workplaces or households, and they understood the role of these instruments in ensuring accuracy and safety. The following section describes how these objects served as forms of science capital.

ICTs. All groups mobilized their ability to use ICTs, in conjunction with other forms of science capital, to advance their engineering projects. As an example, members of Group Five began their project, which was to improve a neighborhood playground, by creating a website in which local residents could access Spanish and English surveys to provide feedback on the changes they would like to see in the playground. To identify trends in these responses, Carlos entered local residents' Spanish and English responses into an online survey service that created circle graphs, bar graphs, and tables that summarized what local residents wanted to see in an improved playground. Carlos then inserted these data displays into a PowerPoint in English, which his group presented in front of a local city council. The group gained access to the council in part by leveraging the connections that Luciana held with the city mayor's wife when they both sat on the same library council. 
In Bourdieusian terms, the participants' ability to use the survey service (an ICT) was a form of objectified capital because it facilitated their efforts in recognizing and quantifying patterns in data and communicating those patterns through visuals. Because many neighborhood residents spoke only Spanish or only English, the participants' ability to create and interpret surveys in both Spanish and English (literacy practices) was a form of embodied capital that enabled the youth to a create design that responded to the needs of both populations. In summary, the group co-mobilized literacy practices in multiple languages, their connections with a mayor's wife (an authority), and their facility with ICTs, and they applied these resources toward the presentation of their proposed playground to the city council.

Measurement tools. The participants used numerous tools, including measurement tools, while constructing devices, maintaining devices, or solving problems in their yards or workplaces. Multiple participants had experienced the consequences of failures with measurement. For instance, Gabriela's family did not carefully measure the height and width of individual steps before installing them in their grandmother's house, and consequently her grandmother had difficulty in descending and ascending the steep and narrow steps. Other failures in measurement had resulted in costly fixes, such as when Gabriela's family destroyed and reconstructed a shed whose flooring area had not been measured correctly.

When designing a wheelchair-accessible swing, Lisa was concerned that, "if it [the wheelchair swing] hits the ground it won't work at all. That's really important. You have to keep them safe." Aware of the dangers and financial losses associated with imprecise measurements when making things, Lisa and Gabriela used tape measures to measure existing swing sets at local parks in order to ensure their wheelchair swing would be safe and in order to ensure they would not have to make the swing twice because their initial measurement was wrong. They 
measured the overall height of the entire swing sets, and the height of the swing seats off of the ground, which varied according to swing (e.g., toddler swing seats were higher than other swing seats). To decide how high the bottom of their swing should be off of the ground and how tall their overall swing set should be, they drew from two sources. First, they considered the height of the various swings they had measured. Second, they conducted virtual tests with a computer model of their swing (using an ICT) and determined which distances would be safe for the occupants, in the sense that swing would not hit the ground and the ramp that led up to the wheelchair from the ground would not be too steep.

In this example, the participants selected and interpreted measuring tools, and they also demonstrated an appreciation of the larger role of measurement in designing safe devices. This appreciation is a form of objectified science capital, which includes the capacity to appreciate the significance of objects in addition to the capacity to interpret these objects and to use them correctly. In this case, the participants mobilized their facility with measurement tools, along with their ability to use ICTs, toward decisions regarding dimensions of the swing set in relation to the swing.

\section{Institutional Capital}

As indicated by Table 3, the groups did not possess institutional science capital to the same extent that they possessed other forms of science capital. However, a few participants held institutional science capital in the forms of titles (e.g., a leadership position in a science-related club) and awards (e.g., a blue-ribbon winner in a technology fair). The participants primarily used this form of capital to establish their legitimacy and credibility with others in the process of advancing and realizing their engineering projects. 
Carmen, for example, was friends with an adult who knew a civil engineer. Carmen's social connection with the engineer was arguably tenuous in the sense that Carmen had not built a relationship with this engineer directly. However, she leveraged her social connections with the adult (an authority), along with mentioning her award-winning science fair project, in order to convince the engineer to help her team generate ideas for their water catchment and filtration project. This engineer in turn introduced her to tools for measuring different pollutants in water, and her team later used these tools to test the efficacy of different water filter designs in relation to different pollutants. In Bourdieusian terms, Carmen co-mobilized her available social and institutional capital in order to gain access to an expert. This expert, in turn, taught her how to use tools that her team had previously not considered, which further informed decisions regarding her group's water filtration system.

\section{Discussion}

A substantial body of research has described how underrepresented youth possess many science-related bodies of knowledge, skills, and resources that can be leveraged in the learning of science. This study contributes to this body of research in at least three ways. First, we offer implications for expanded definitions of science capital, including definitions that more robustly account for youths' multi-lingual literacy practices and diverse social connections. Second, we describe how youth co-mobilized sets of science-related resources toward the acquisition of future capital. Third, we describe how engineering practices fostered the activation and legitimization of multiple forms of science capital.

Expanded definitions of science capital. Our codes verified many categories in existing descriptions of science capital, such as formal scientific knowledge as a form of embodied capital. However, our coding scheme resulted in new identifications of science capital mobilized 
by the participants. In particular, this coding scheme identified how participants often mobilized literacy practices, including the ability to read and write in Spanish, to acquire information from people and texts, and to communicate with English- and Spanish-speaking clients in order to produce responsive engineering designs.

Previous conceptions of science capital have defined scientific literacy as "incorporating scientific knowledge, skills, and an understanding of how science 'works' and the ability to use and apply these capabilities in daily life for personal and social benefit" (Archer et al., 2015, p. 8). This definition of literacy is consonant with what Norris and Phillips (2003) call 'derived' science literacy, or literacy that stems from 'fundamental literacy,' which includes the ability to interpret, produce, and use scientific texts.

The study indicates that fundamental literacy skills — or the ability to locate and interpret helpful texts and to produce and share texts with stakeholders-were essential to the advancement of the participants' engineering designs. Through texts, the participants solicited ideas in their communities; through texts, they learned scientific information they did not previously know; through texts, they communicated to powerful people who had the capacity to actualize their design ideas. Thus, we argue that the ability to locate, interpret, use, and produce scientific texts for different audiences may be an important form of science capital that can advance youths' science aspirations. The youths' multilingualism was an asset in this regard because they had access to communicating with wider audiences beyond people who spoke only English. Through their use of Spanish literacy practices, for example, they were able to design a playground that accounted for the perspectives of numerous Spanish-speaking local residents, and responsiveness to clients is important to producing quality engineering designs (Leydens \& Lucena, 2009; Walther, Miller, \& Sochacka, 2017). 
This study also pointed toward other previously unidentified forms of science capital mobilized by the youth, such as their connections with authorities. Much as Latour (1987) found that social and political connections with the right people can advance scientists' aspirations and grantsmanship, we found that the youth leveraged their connections with people who had the economic capacity and/or institutional authority to actualize their engineering projects. Thus, social science capital may not only include knowing people who know science and who know how to obtain degrees in science, as has previously been identified, but also knowing people who can actualize scientific products through funding or other means. Finally, this study suggested that youth may leverage institutional capital, such as science-related awards or titles, toward science-related aspirations.

Co-mobilization of science capital. In addition to identifying previously unidentified forms of science capital, this study also provides descriptions of how the youth co-mobilized these forms of capital as part of larger configurations of science capital. The examples in the findings illustrate that, in most cases, the mobilization of one form of capital alone was not adequate for advancing the engineering projects; instead, groups co-activated embodied, social, and/or objectified capital toward the attainment of the same sub-goal in relation to their engineering project (e.g., deciding on a material).

Moreover, at times, activation of particular forms of capital seemed dependent on the activation of other forms of capital. For instance, Sofia was able to conduct a successful Internet search (embodied capital: literacy practice) because a community member had previously told her the formal names of promising materials to search for (social capital: expert). Carmen was able to measure pollutants in water (objectified capital: measuring tool) because an engineer told her how to do it (social capital: expert), but she only gained access to that engineer through first 
establishing her credibility (institutional capital: award) and through citing her connections with a friend of the engineer (social capital: authority).

These examples and numerous others suggest that configurations of science capital are not only synergistic but originative, in the sense that the co-mobilization of particular forms of capital may actually enable the activation of future forms of capital. In other words, youth may not have access to particular forms of capital (e.g., embodied capital in the form of knowledge of helpful Internet search terms or knowledge of applicable formulas) until they first activate other sources of capital (advice from experts), and newly activated capital can in turn enable the coactivation of subsequent forms of science capital in a forward-moving chain.

Because this study suggests that youths' mobilization of science resources may depend on the co-activation or prior activation of other science resources, we argue that classroom educators or educators in informal settings might adopt a holistic, rather than discrete, view of youths' science-related resources. Acting in accordance with this view, educators would encourage youth to mobilize multiple resources in conjunction with each other, which in turn may facilitate the co-activation and future activation of other science resources. Much previous research has described how educators can leverage one or two discrete science resources in their classrooms, such as familial knowledge (Licona, 2013) or participants' languages and everyday methods of sensemaking (Warren, Ballenger, Ogonowski, Rosebery, \& Hudicourt-Barnes, 2001). We argue that this existing research might be expanded through a more robust consideration of how youth possess broad and interconnected configurations of embodied, social, objectified, and institutional capital — all of which can be legitimized and encouraged to advance youths' science-related aspirations. 
Engineering Practices and Science Capital. Although the NGSS identified engineering as a tool for promoting equity and diversity in science, we argue that its authors may not have fully explored or explained the means through which engineering promotes equity and diversity. This study highlights particular ways in engineering can serve to validate underrepresented youths' diverse resources as valuable assets to doing science. Certainly, this study joins other studies (e.g. Lim \& Calabrese Barton, 2006; Rodriguez \& Berryman, 2002) in confirming that engineering demonstrates how science can be used to transform problems that affect students' lives and communities. Like other studies (e.g., Calabrese Barton \& Tan, 2009; Fusco, 2001), this study also confirms that underrepresented youth possess and can activate experientially and culturally-derived knowledge related to science, such as knowledge of caring for gardens.

However, engineering requires more than science-related knowledge; instead, practitioners must apply a range of bodies of knowledge and skills, such as deep social and geographic knowledge of the communities that are being served (Walther et al., 2017), and the ability to listen to, understand, and empathize with diverse clients (Leydens \& Lucena, 2009). For this reason, we argue that engineering, as a vehicle for learning science, enabled the participants' multilingualism to become important assets to the doing of science. The participants' ability to communicate in Spanish with clients was a valued form of capital because it enabled the youth to produce designs that met the needs of people in their communities, not just designs that were scientifically or mathematically viable. In fact, the city council who listened to Group Five's playground idea specifically praised them for collecting data from a broad cross-section of residents, versus exclusively collecting data from those who spoke primarily English. Thus, we argue that because engineering as a discipline requires responsiveness to clients, the participants' ability to communicate in reading and writing with 
linguistically diverse clients became an asset that enabled them to advance a science-related aspiration.

Engineering validated and enabled the activation of multiple forms of science capital in other ways as well. Engineering requires the application or actualization of science and mathematics (Dym, Little, \& Orwin, 2014), and not just the possession of de-contextualized or abstract knowledge. Accordingly, we found that the participants mobilized science-related resources related to the actualization of their projects in addition to science-related resources that helped them develop the knowledge base related to their products. For instance, Group Two's science teacher was an important resource that helped them remember a formula for calculating force, but their principal was also an important resource who helped introduce them to district stakeholders who could potentially fund and realize their ideas. Because of engineering's focus on actualization, we argue that the participants had opportunities to activate a wide range of social resources, including people who did not necessarily possess a knowledge of science but who were important to advancing their science-related aspirations nonetheless.

Archer and colleagues (2015) stated that dominant groups value some forms of science, such as doing experiments or attending museums, as being "more scientific" than other forms of science, such as cooking or tinkering. This hierarchy of "what counts as science" often works to de-legitimize or undervalue the science-related practices of underrepresented youth. We argue that engineering worked to dismantle this hierarchy. Throughout the engineering projects, the youth mobilized their existing science-related skills and bodies of knowledge (e.g., knowledge of gardening, knowledge of measurement tools); mobilized knowledge related to maintenance and construction (e.g., the custodian's knowledge of regulations related to doors); mobilized their existing facility with digital technologies (e.g., their ability to use a survey tool to communicate 
results to clients); and mobilized their ability to understand and produce information in multiple languages.

All of these resources were legitimized in the sense that they were all important contributors toward the development and communication of a high-status, science-related goal: the production of an engineering project. These engineering projects, in turn, led to additional forms of distinction and capital, such as three groups' experiences being published in local newspapers, and such as several participants being accepted to college or leadership seminars after writing about their engineering projects on their application letters. This study therefore demonstrates that engineering may recast youths' resources, which may not typically be considered as high status or scientific, as potentially valuable vehicles for achieving esteemed science-related goals.

\section{Conclusion}

In their previous research, Archer and colleagues (2015) stated that science capital is "a potential vehicle for dismantling and restructuring current unequal relations of power: to help create contexts in which other (wider, different) forms of capital might be valued" (p. 22). This study identified wider and deeper forms of capital than has previously been identified in literature in science capital. These forms of capital included multilingual literacy practices and connections with authorities, which advanced underrepresented youths' science-related aspirations.

At the same time, many scholars assert that capital is only valuable insofar as it is acknowledged within a given field or context. Accordingly, we repeat Archer and colleagues' (2015) previous call for stakeholders to "create contexts" in which underrepresented youths' 
resources are recognized and treated as important forms of capital in supporting science-related aspirations. We envision engineering as one such context for learning science.

Engineering has the potential to demonstrate that a wide variety of skills and resources are needed to actualize science in local and global communities. Many underrepresented youthwho may speak the language of people in their communities, know a range of people in their communities, and recognize and understand problems facing under-served populations in their communities - possess a range of skills, connections, and bodies of knowledge that are invaluable for the actualization of science in the community. As a vehicle for learning science, engineering may provide opportunities for youths' science-related resources to be recognized, legitimized, applied, and valued.

Acknowledgement of Funding Source: This material is based upon work supported by the National Science Foundation under Grant Number 1222566. Any opinions, findings, and conclusions or recommendations expressed in this material are those of the authors and do not necessarily reflect the views of the NSF. 


\section{References}

Archer, L., Dawson, E., DeWitt, J., Seakins, A., \& Wong, B. (2015). "Science capital”: A conceptual, methodological, and empirical argument for extending Bourdieusian notions of capital beyond the arts. Journal of Research in Science Teaching, 52, 922-948.

Archer, L., DeWitt, J., Osborne, J., Dillon, J., Willis, B., \& Wong, B. (2012). Science aspirations, capital, and family habitus: How families shape children's engagement and identification with science. American Educational Research Journal, 49, 881-908.

Archer, L., DeWitt, J., \& Willis, B. (2014). Adolescent boys' science aspirations: Masculinity, capital, and power. Journal of Research in Science Teaching, 51, 1-30.

American Association for the Advancement of Science. (1989). Science for all Americans. New York: Oxford University Press.

Basu, S. J., \& Calabrese Barton, A. (2007). Developing a sustained interest in science among urban minority youth. Journal of Research in Science Teaching, 44, 466-489.

Bourdieu, P. (1984). Distinction: A social critique of the judgment of taste. Cambridge, MA: Harvard University Press.

Bourdieu, P. (1986). The forms of capital. In J. G. Richardson (Ed.), Handbook of theory and research for the sociology of education (pp. 241-258). New York, NY: Greenwood Press.

Bourdieu, P. (1998). Practical reason: On the theory of action. Stanford, CA: Stanford University Press.

Bourdieu, P., \& Wacquant, L. J. D. (1992). An invitation to reflexive sociology. Chicago, IL: University of Chicago Press.

Brown, S., Flick, L., \& Fiez, T. (2009). An investigation of the presence and development of social capital in an electrical engineering laboratory. Journal of Engineering Education, 98, 93-102.

Bybee, R. W. (2011). Scientific and engineering practice in K-12 classrooms. Science Teacher, $78,34-40$.

Calabrese Barton, A., \& Tan, E. (2009). Funds of knowledge and Discourses and hybrid space. Journal of Research in Science Teaching, 46, 50-73.

Carrington, V., \& Luke, A. (1997). Literacy and Bourdieu's sociological theory: A reframing. Language and Education, 11, 96-112.

Cherng, H.-Y. S., Calarco, J. M., \& Kao, G. (2013). Along for the ride: Best friends' resources and adolescents' college completion. American Educational Research Journal, 50, 76106.

Claussen, S., \& Osborne, J. (2013). Bourdieu's notion of cultural capital and its implications for the science curriculum. Science Education, 97, 58-79.

Compton-Lilly, C. (2007). The complexities of reading capital in two Puerto Rican families. Reading Research Quarterly, 42, 72-98.

Davis, K. S. (2001). "Peripheral and subversive": Women making connections and challenging the boundaries of the science community. Science Education, 85, 368-409.

Dym, C. L., Agogino, A. M., Eris, O., Frey, D. D., \& Leifer, L. J. (2005). Engineering design thinking, teaching, and learning. Journal of Engineering Education, 94, 103-120.

Dym, C.L., Little, P., \& Orwin, E.J. (2014). Engineering design: A project based introduction (4th ed). Danvers, MA: Wiley.

Fuller, R. L. (2011). African American students' perception of the development of social capital in a science, technology, engineering, and mathematics (STEM) pre-college program. Ann Arbor, MI: ProQuest, UMI Dissertation Publishing. 
Fusco, D. (2001). Creating relevant science through urban planning and gardening. Journal of Research in Science Teaching, 38, 860-877.

Gorard, S., \& See, B. H. (2009). The impact of socio-economic status on participation and attainment in science. Studies in Science Education, 45, 93-129.

Greenwood, C., Harrison, M., \& Vignoles, A. (2011). The labour market value of STEM qualifications and occupations: London, UK: Institute of Education/Royal Academy of Engineering.

Hammond, L. (2001). Notes from California: An anthropological approach to urban science education for language minority families. Journal of Research in Science Teaching, 38, 983-999.

Kiyama, J. M. (2010). College aspirations and limitations: The role of educational ideologies and funds of knowledge in Mexican American families. American Educational Research Journal, 47, 330-356.

Kramsch, (2008). Pierre Bourdieu: A biographical memoir. In J. Albright \& A. Luke (Eds.), Pierre Bourdieu and literacy education (pp. 33-49). New York, NY: Routledge.

Lareau, A. (2011). Unequal childhoods: Class, race, and family life (2nd ed.). Oakland, CA: University of California Press.

Latour, B. (1987). Science in action: How to follow scientists and engineers through society. Cambridge, MA: Harvard University Press.

Leydens, J. A., \& Lucena, J. C. (2009). Listening as a missing dimension in engineering education: Implications for sustainable community development efforts. IEEE Transactions on Professional Communication, 52, 359-376.

Lichtenstein, G., Chen, H. L., Smith, K. A., \& Maldonado, T. A. (2014). Retention and persistence of women and minorities along the engineering pathway in the United States. In A. Johri \& B. M. Olds (Eds.), Cambridge handbook of engineering education research (pp. 311-334). New York, NY: Cambridge University Press.

Licona, M. M. (2013). Mexican and Mexican-American children's funds of knowledge as interventions into deficit thinking: Opportunities for praxis in science education. Cultural Studies of Science Education, 8, 859-872.

Lim, M., \& Calabrese Barton, A. (2006). Science learning and a sense of place in an urban middle school. Cultural Studies of Science Education, 1, 107-142.

Lin, N. (2000). Inequality in social capital. Contemporary Sociology, 29, 785-795.

Lin, N. (2001). Social capital: A theory of social structure in action. Cambridge, UK: Cambridge University Press.

Lopez, G. (2001). The value of hard work: Lessons on parental involvement from an (im)migrant household. Harvard Educational Review, 71, 416-437.

Lubienski, S. T. (2003). Celebrating diversity and denying disparities: A critical assessment. Educational Researcher, 32, 30-38.

Lung, F., Potvin, G., Sonnert, G., \& Sadler, P. M. (2013). Welcome to America, welcome to college: Comparing the effects of immigrant generation and college generation on physical sciences and engineering career intentions. American Institute of Physics Conference Proceedings, 1513, 270-273.

Martin, J. R. (1998). Discourses of science: Recontextualization, genesis, intertextuality, and hegemony. In J. R. Martin \& R. Veel (Eds.), Reading science: Critical and functional perspectives on discourses of science (pp. 3-14). New York, NY: Routledge. 
Martin, J. P. (2015). The invisible hand of social capital: Narratives of first generation college students in engineering. International Journal of Engineering Education, 31, 1170-1181.

Martin, J. P., Simmons, D. R., \& Yu, S. L. (2013). The role of social capital in the experiences of Hispanic women engineering majors. Journal of Engineering Education, 102, 227-243.

Maulucci, M. S. R., Brown, B. A., Grey, S. T., \& Sullivan, S. (2014). Urban middle school students' reflections on authentic science inquiry. Journal of Research in Science Teaching, 51, 1119-1149.

Miles, M. B., \& Huberman, A. M. (1994). Qualitative data analysis: An expanded sourcebook (2nd ed.). Thousand Oaks, CA: Sage.

Moll, L. C., Amanti, C., Neff, D., \& González, N. (1992). Funds of knowledge for teaching: Using a qualitative approach to connect homes and classrooms. Theory into Practice, 31, $132-141$.

Naidoo, R. (2004). Fields and institutional strategy: Bourdieu on the relationship between higher education, inequality, and society. British Journal of Sociology of Education, 25, 457471.

National Center for Educational Statistics. (2012). New Americans in postsecondary education: A profile of immigrant and second-generation American undergraduates. Washington DC: Institute of Education Sciences. Retrieved from: http://nces.ed.gov/pubs2012/2012213.pdf

National Science Board. (2016). Science and engineering indicators. Arlington, VA: Author. Retrieved from: https://nsf.gov/statistics/2016/nsb20161/\#/

National Research Council. (2012). A framework for K-12 science education: Practices, crosscutting concepts, and core ideas. Washington, DC: National Academy Press.

NGSS Lead States. (2013). Next Generation Science Standards: For states, by states. Washington, DC: The National Academies Press.

Norris, S. P., \& Phillips, L. M. (2003). How literacy in its fundamental sense is central to scientific literacy. Science Education, 87, 224-240.

Pawley, A. L. (2009). Universalized narratives: Patterns in how faculty members define “engineering." Journal of Engineering Education, 98, 309-319.

Prewitt, A., Eugene, W., \& Daily, S. (2007, June). Minority retention and success in engineering: Diversifying the pipeline through the development of social capital. Paper presented at the 2007 Annual Conference of the American Society for Engineering Education, Honolulu, HI. Retrieved from: https://peer.asee.org/2374

Reay, D., David, M., \& Ball, S. (2005). Degrees of choice: Social class, race and gender in higher education. Stoke-on-Trent, UK: Trentham Books.

Rios-Aguilar, C., Kiyama, J. M., Gravitt, M., \& Moll, L. (2011). Funds of knowledge for the poor and forms of capital for the rich? A capital approach to examining funds of knowledge. Theory and Research in Education, 9, 163-184.

Rodriguez, A. (2015). What about a dimension of engagement, equity, and diversity practices? A critique of the Next Generation Science Standards. Journal of Research in Science Teaching, 52, 1031-1051.

Rodriguez, A. J., \& Berryman, C. (2002). Using sociotransformative constructivism to teach for understanding in diverse classrooms: A beginning teacher's journey. American Educational Research Journal, 39, 1017-1045. 
Ruiz-de-Velasco, J., Fix, M., \& Clewell, B. C. (2000). Overlooked and underserved: Immigrant students in U.S. secondary schools. Washington, DC: The Urban Institute. ED449275. Retrieved from: http://www.urban.org/UploadedPDF/overlooked.pdf

Saldaña, J. (2015). The coding manual for qualitative researchers ( $3^{\text {rd }}$ ed.). Los Angeles, CA: Sage.

Skeggs, B. (2004). Class, self, culture. London, UK: Routledge.

Smith, J. M., \& Lucena, J. C. (2016). "How do I show them I'm more than a person who can lift heavy things?" The funds of knowledge of low income first generation engineering students. Journal of Women and Minorities in Science and Engineering, 22, 199-221.

Vélez-Ibáñez, C. G., \& Greenberg, J. B. (1992). Knowledge and transformation of funds of knowledge among U.S.-Mexican households. Anthropology \& Education Quarterly, 23, 313-335.

Walther, J., Miller, S. E., \& Sochacka, N. W. (2017). A model of empathy as a core skill, practice orientation, and professional way of being. Journal of Engineering Education, 106, 123-148.

Walther, J., Sochacka, N. W., \& Kellam, N. N. (2013). Quality in interpretive engineering education research: Reflections on an example study. Journal of Engineering Education, 102, 626-659.

Warren, B., Ballenger, C., Ogonowski, M., Rosebery, A. S., \& Hudicourt-Barnes, J. (2001). Rethinking diversity in learning science: The logic of everyday sense-making. Journal of Research in Science Teaching, 38, 529-552.

Wilson-Lopez, A., Mejia, J. A., Hasbún, I. M., \& Kasun, G. S. (2016). Latina/o adolescents' funds of knowledge related to engineering. Journal of Engineering Education, 105, 278311.

Yin, R. K. (2014). Case study research: Design and methods (5 $5^{\text {th }}$ ed.). Los Angeles, CA: Sage.

Zimmerman, H. T., \& Weible, J. L. (2017). Learning in and about rural places: Connections and tensions between students' everyday experiences and environmental quality issues in their community. Cultural Studies of Science Education, 12, 7-31. 